\title{
Chondrosarcoma of Sphenoid Sinus: A Case Report
}

\author{
Gharnati. $\mathrm{K}^{1^{*}}$, Bamine. $\mathrm{H}^{1}$, Mehdaoui. $\mathrm{S}^{1}$, Zaki.Z ${ }^{1}$, Alami.Mn ${ }^{1}$
}

${ }^{1}$ Department of ENT, Maxillo-Facial, Reconstructive and Plastic Surgery, Hassan II Hospital University, Fez, Morocco

DOI: $10.36347 /$ sasjs.2021.v07i04.013

| Received: 27.02.2021 | Accepted: 14.04.2021 | Published: 26.04.2021

*Corresponding author: Gharnati $\mathrm{K}$

Abstract

Case Report

Chondrosarcoma is a highly destructive malignant tumor of cartilaginous, bone and mesenchymal origin. Its localization in the head and neck is rare while localization in the nasal sinus site is even rarer. Only about 20 such cases have been reported in the literature, and they were located in the maxillary and sphenoidal sinuses. Its clinical presentation is non-specific. It poses a therapeutic problem because of its location at the base of the skull. We hereby present a case of grade II chondrosarcoma of shenoid sinus. The aim of our work is to describe the epidemiological, clinical, radiological and anatomopathological profile as well as the therapeutic management of this pathological entity through a review of the literature.

Keywords: CHONDROSARCOMA, malignant tumor, sphenoid sinus, imaging, surgery.

Copyright $\left({ }_{0} 2021\right.$ The Author(s): This is an open-access article distributed under the terms of the Creative Commons Attribution 4.0 International License (CC BY-NC 4.0) which permits unrestricted use, distribution, and reproduction in any medium for non-commercial use provided the original author and source are credited.

\section{INTRODUCTION}

Chondrosarcoma is a primary malignant tumor of the bone that produces tumor cartilage without ever developing tumor bone tissue [1]. It accounts for 10 to $20 \%$ of malignant bone tumors [1] and only $7 \%$ of them occur in the head and neck region [2]. The nasal sinus location is rare: only about twenty cases have been reported in the literature [3]. We report the case of a patient treated in our department.

\section{PATIENT AND OBSERVATION}

A 29-year-old women, admitted for right nasal obstruction, evolving for 1 year before her admission, reported complications are the onset of ipsilateral blindness without other associated signs or epistaxis. During the physical examination, nasal flow was reduced on the two sides, with higher severity on the right. The nasal endoscopy showed the presence of a budding polyploid mass, pedicled in the sphenoid sinus occupying the upper half of the right nasal fossa reaching the height of the middle turbinate (FIGURE 1). The ophthalmologic examination revealed the presence of right blindness with visual acuity preserved on the contralateral side. The CT scan showed the presence of a hypodense tissue process centered on the body of the sphenoid, with irregular contours measuring $51 * 32 * 55 \mathrm{~mm}$ not enhancing after injection of the contrast product with thinning of the bone walls and rupture of the cortex in places. The MRI confirmed the presence of the heterogeneous lobulated expansive lesion, hyper $\mathrm{T} 1$ hypo $\mathrm{T} 2$, in the body of the right sphenoid with extension to the nasal fossae and the ethmoid cells and with infiltration of the right optic nerve at the level of the optic canal (FIGURE 2 and 3). An endonasal surgery was performed on the patient with excision by tumor's fragmentation. The anatomopathological and immunohistochemical study favored a well differentiated grade II chondrosarcoma. Postoperative nasal sinus CT was satisfactory with no tumor residue (FIGURE 4). The patient was referred for adjuvant radiotherapy with a good clinical outcome with a follow-up of 2 years.

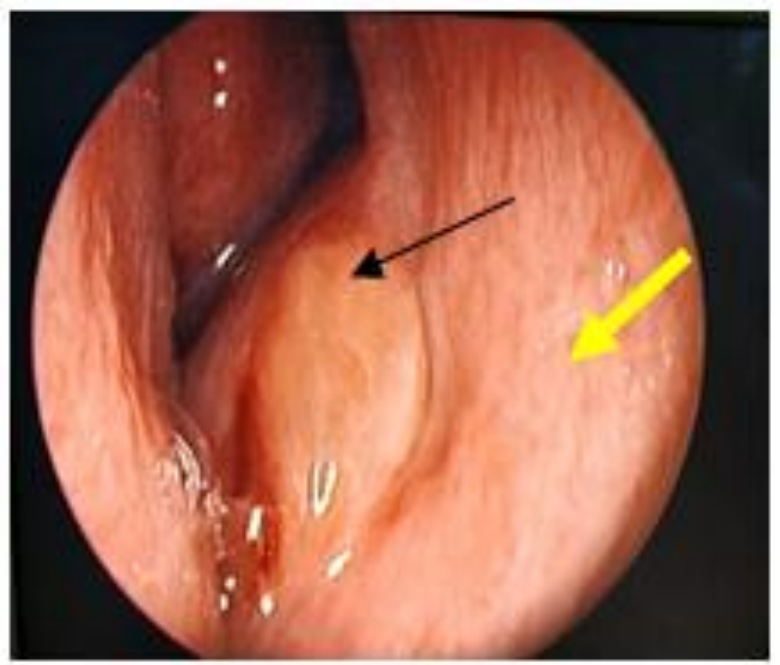

Fig-1: Endoscopic view of the right nasal cavity (black arrow: submucosal tumor pushing back the nasal septum, yellow arrow: nasal septum) 


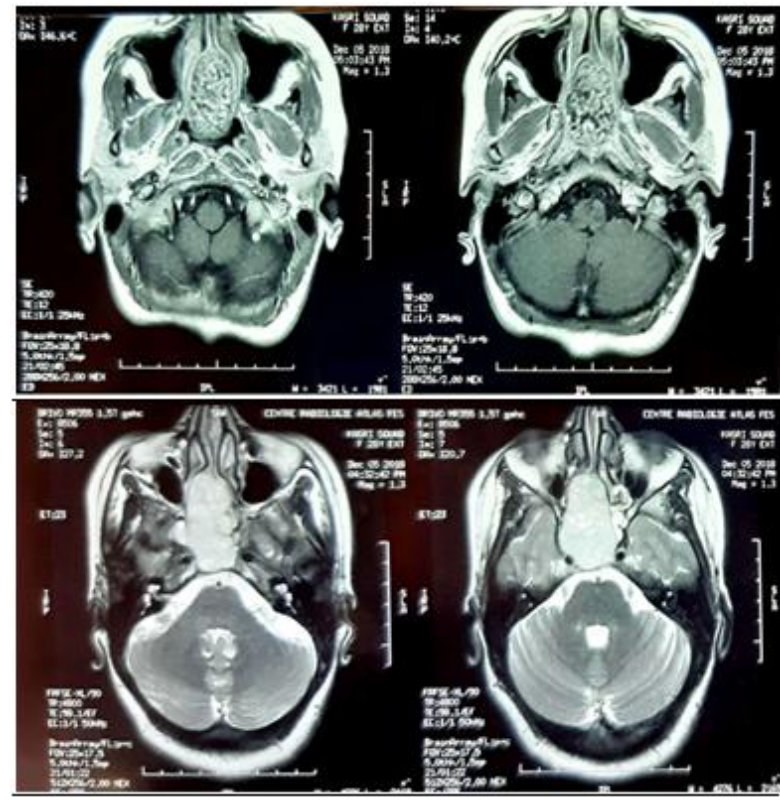

Fig-2 and 3: T1 and T2 axial slice MRI showing the process of the sphenoid sinus

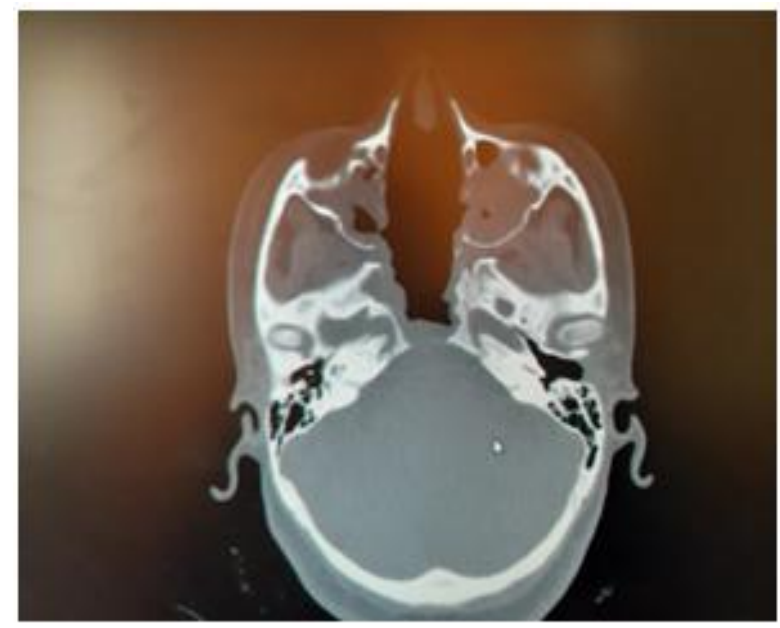

Fig-4: facial CT after surgery (after 1year)

\section{DISCUSSION}

Chondrosarcoma is a rare malignant tumor. It accounts for 10 to $20 \%$ of malignant bone tumors [1]. Localization at Sinus level is very rare: around twenty cases have been reported in the literature, including 10 by $\mathrm{Fu}$ and Perzin in 1974 [3]. The incidence increases with age where the peak occurs in the fourth decade [1], with a clear predominance among women, differently from other Chondrosarcoma's locations [4].

Chondrosarcomas tend to be large at presentation [5]. Their symptomatology varies according to the site and size of the tumor. The symptoms are usually nasal obstruction, nasal discharge, facial asymmetry, headache, restricted ocular movements, diplopia, proptosis, facial pain and ear fullness. Extension of the lesion with intracranial involvement is characterized by loss of vision, proptosis and multiple cranial nerve involvement [5].
Radiological imaging is essential before attempting surgical intervention. Computer Tomographic (CT) scan in coronal and sagittal plain is the most informative investigation [6] for evaluating the exact location of the tumour and its extension if any [7]. The MRI specifies the extension to essential sensory and vital soft tissues; it differentiates between granulomatous tissues and recurrences during the monitoring of operated chondrosarcomas [8].

Chondrosarcomas arises from primitive mesenchymal stem cells or may arise in tissues known to be formed of cartilage from nests that remain after ossification. In their gross appearance, the neoplasm is well circumscribed, ovoid, lobular, and with gelatinous masses. A fibrous capsule may be present. Hemorrhage may occur giving it a look of hematoma. The average size of lesion may be $3-8 \mathrm{~cm}$ on presentation [9].

Lesions are graded 1-3 depending on the amount and maturity of cartilage and the connective tissues's anaplasticity. Grade 2 and 3 are marked by myxoid tissue and cystic degeneration consisting of proliferating plump chondroblast or spindle shaped mesenchymal cell and abnormal cartilage. The histological grading by cellularity, nuclear size and mitotic rate is reported to correlate with the rate of distant metastasis and overall survival [10].

Although the histological appearances of this tumour are generally characteristic, a differential diagnosis of chondroma, chordoma, and chondromyxoid fibroma should be considered. It is not unusual for a fine needle biopsy or even an excision biopsy to be unreliable since the specimen may not be representative of the lesion as areas of cellular atypism may be restricted only to certain parts of a well differentiated chondrosarcoma [11]. Therefore, it is important to evaluate multiple fields to grade these tumours accurately [12]. Biopsy of the lesion is the only way to confirm the diagnosis.

Surgery remains key to the treatment. Maximal surgery is required in the chondrosarcomas. However, to achieve an optimal surgery, several interventions are often required which might lead to an increased risk of complications.

The endoscopic way is the first choice of the treatment of sphenoid chondrosarcomas [13]. Because of this high risk of complications associated with wide resection, limited removal is usually proposed. A large debulking allows for safer irradiation away from surrounding critical organs. Adjuvant radiation therapy is also prescribed with excellent results compared to surgery alone [14].

Concerning radiation therapy, the efficacy of treatment is difficult to analyze for different reasons: the rareness of the tumors, the long history of the 
disease, the variety of treatment procedures with updated techniques finally the series mix of chordoma and chondrosarcomas. Nevertheless, the required doses to control the disease significantly exceed the dose constraints for critical organs. Proton therapy is considered the optimal method for dose gradient irradiation to irregularly shaped targets closely juxtaposed to critical organs. Proton therapy has been used mainly with conventional fractionation at doses between 67 and 83 Gy [15].

The prognosis depends upon the location and extent of the lesion, adequacy of treatment and degree of differentiation. Patients with incomplete resections requiring further radiotherapy or chemotherapy have a bad prognosis [16]. Survival varies from $44 \%$ to $81 \%$ for chondrosarcoma of the head and neck region. The 10 -year survival rate is less than $30 \%$ for all bone and extra-skeletal locations. Recurrence is $40-60 \%$. The course is marked by local recurrences and especially pulmonary metastases, sometimes very late onset.

\section{CONCLUSION}

Chondrosarcoma is a malignant tumor whose localization in the sinuses is very rare. Symptoms vary depending on the location and the expansion level. MRI is the key examination method to make the diagnosis. The treatment is mainly surgical. The effectiveness of radiochemotherapy has not been demonstrated thus far, but many authors recommend its use in addition to surgery. Recurrences are frequent as well as metastases (pulmonary ++) which makes chondrosarcoma a malignant tumor with a poor prognosis.

\section{Conflict of interests}

The authors declare no conflicting interests.

\section{REFERENCES}

1. Pontes H, Pontes F, de Abreu M, de Carvalho P, de Brito Kato A, Fonseca F. Clinicopathological analysis of head and neck chondrosarcoma: three case reports and literature review. Int $\mathbf{J}$ Oral Maxillofac Surg. 2012; 41:203-10.

2. Khan F, Mari A, Afzal R. Sphenoidal intracranial chondrosarcoma. J Coll Physicians Surg Pak. 2014;24:S34-6

3. Fu Y, Perzin K. Non-epithelial tumors of the nasal cavity, paranasal sinuses, and nasopharynx: a clinicopathologic study. 3. Cartilaginous tumors (chondroma, chondrosarcoma). Cancer. 1974;34:453-63

4. Koch B, Karnell L, Hoffman H, Apostolakis L, Robinson R, Zhen W,. National cancer database report on chondrosarcoma of the head and neck. Head Neck. 2000;22:408-25

5. Sharma K, Kaur A, Taneja HC, Tyagi I, Pandey R. Nasal septal chondrosarcoma with visual loss. Indian J Ophthalmol. 1993;41(4):189-191

6. Jaswal A, Jana AK, Sikder B. Chondrosarcoma of nose and paranasal sinus-a rare presentation. Indian J Otolaryngol Head Neck Surg. 2008; 60(3):284-286

7. Downey TJ, Clark SK, Moore DW. Chondrosarcoma of the nasal septum. Otolaryngol Head Neck Surg.2001; 125(1):98-100

8. Lioyd G, Lund VJ, Howard D, Savy L. Optimum imaging for sinonasal malignancy. J Laryngol Otol. 2000;114(7):557-62

9. Kavita Sachdeva, Neeraj Sachdeva. Myxoid Chondrosarcoma of Nasomaxilloethmoid Region with Intracranial Extension Indian $\mathrm{J}$ Otolaryngol Head Neck Surg. 2016: 68(1):110-114;

10. Evans HL, Ayala AG, Romsdahl MM. Prognostic factors in chondrosarcoma of bone: a clinicopathologic analysis with emphasis on histologic grading. Cancer. 1977; 40:818-831.

11. Ashley DJB. Temperomandibular juxtaarticular chondroma: case report. In: Evans' histological appearance of tumours, 4th edn. London, Livingstone. 1990; 133-139

12. Alho A, Connor JF, Mankin HJ. Assessment of malignancy of cartilaginous tumours using flow cytometry. A preliminaw report. J Bone Joint surg. 1983; 65A:779-785

13. Guo L, Liu J, Sun X, Wang D. Sinonasal tract chondrosarcoma: 18-year experience at a single institution. Auris Nasus Larynx. 2014;41:290-3

14. Boskos C, Feuvret L, Noel G. Combined proton and photon conformal radiotherapy for intracranial atypical and malignant meningioma. Int $\mathbf{J}$ Radiat Oncol Biol Phys. 2009; 75:399-406.

15. Georges Noel, Vinai Gondi. Proton therapy for tumors of the base of the skull Chinese Clinical Oncology. Chin Clin Oncol. 2016;5(4):51

16. Ruark DS, Schlehaider UK, Shah JP. Chondrosarcomas of the head and neck. World $\mathrm{J}$ Surg.1992; 16:1010-1016. 